\title{
Non-Surgical Treatment Options for Peyronie's Disease
}

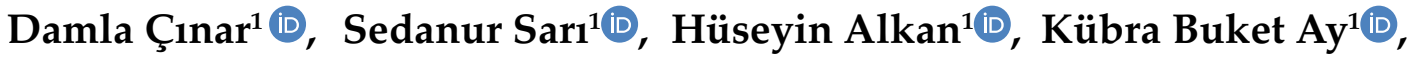 \\ Enes Borcaktepe $^{1} \mathbb{D}^{D}$, Ahmet Yiğit Duyum ${ }^{1} \mathbb{D}$, Sude Sevcan Filikçi ${ }^{1} \mathbb{D}$, Eren Gençer ${ }^{1} \mathbb{D}^{\mathbb{D}}$, \\ Çağla Senem ${ }^{1} \mathbb{D}$, Serhat Soylu' ${ }^{1}$, Şeyma Tuna ${ }^{1} \mathbb{D}$, Rabia Tuncer ${ }^{1} \mathbb{D}^{\mathbb{D}}$,

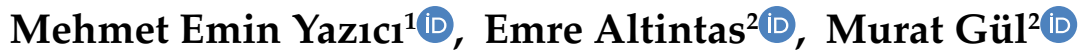

1 Selçuk University Faculty of Medicine, 2020- Evidence Based Medicine-Group 3D, Konya, Turkey

2 Selçuk University Faculty of Medicine, Department of Urology, Konya, Turkey

\begin{abstract}
Peyronie's disease, which occurs with the formation of a fibrous plaque in the tunica albuginea; is a disease that causes some physical problems such as bending and shortening of the penis. There are surgical treatment methods of this disease as well as non-surgical treatment methods. Non-surgical treatment methods, which are grouped under six headings: oral treatments, topical treatments, traction and vacuum treatments, shock wave therapy, intraplate injection treatments, and experimental treatments, can be preferred in cases where the symptoms are not very advanced because they provide advantages in terms of ease of application, accessibility, and cost. Although the only non-surgical treatment method approved by the FDA (U.S. Food and Drug Administration) yet is clostridium collagenase histolikum, which is used in intraplaque injection, studies have shown that other methods also reduce curvature, pain, and plaque volume.
\end{abstract}

Keywords: Peyronie's Disease, Non-Surgical Treatment, Plaque.

\section{INTRODUCTION}

Fibrous plaque formation in the tunica albuginea layer surrounding the corpus cavernosum causes Peyronie's disease, although its pathological mechanism has not been fully elucidated. The disease was first described by Francois Gigot de La Peyronie in 1743. The disease, characterized by penile curvature, pain, erectile dysfunction, penile shortening, and deformity, has two phases, acute and chronic. While there is active inflammation in the acute phase, the lesion stabilizes in the chronic phase. Plaque calcification occurs after the inflammatory response resulting from vascular damage in the tunica albuginea (1). In the tissue under the microscope, increased connective tissue and inflammatory cells are seen. The prevalence of the disease, which varies between $3.2 \%$ and $13 \%$ in studies, is generally seen in men between the ages of 50-60 (2). It should also be considered that patients may not apply to health institutions due to psychosocial or cultural reasons. While Peyronie's disease is associated with increased 
Dupuytren's contractures, plantar facial contractures (Ledderhose disease), tympanosclerosis, trauma, transurethral procedures, diabetes, gout, Paget's disease, and even beta-blocker use, the exact etiology is unknown. Still, penile trauma, genetic conditions, and genital system diseases thought that three main factors, including the history of the disease, increase the risk of the disease (3). In recent years, it has been stated that the increase in TGF- $\beta$ expression is also effective in its pathological mechanism (4). The treatment of this disease, which affects patients psychologically by causing problems such as lack of selfconfidence, anxiety, and depression, in addition to physical problems very important for improving the quality.

Although surgical applications may be preferred in patients with advanced symptoms, non-surgical treatment options can be advantageous when conditions such as ease of application, easy accessibility, and cost are taken into account. In the guidelines published by the EAU (European Association of Urology) and AUA (American Urological Association), there are tables with suggestions about which method would be more beneficial to use, and studies are still being carried out on the effectiveness of these methods.

\section{Search strategy and selection criteria}

Articles on non-surgical treatment methods in the treatment of Peyronie's disease have been reviewed and compiled, emphasizing being up to date. The therapeutic agents' efficacy was discussed with the summaries given at the end of each non-surgical treatment method.

\section{ORAL TREATMENT METHODS}

\section{Vitamin E}

\section{Mechanism}

Acting as a natural antioxidant, vitamin $\mathrm{E}$ acts by reducing the number of oxygen-free radicals produced during cellular metabolism. Lipid peroxides are selective and potent inhibitors of prostacyclins. Vitamin E fulfills its antioxidant effect by preventing the peroxidation of lipid peroxides. It is still a popular treatment modality due to its low cost and relatively mild side effects $(5,6)$.

\section{Evidence}

In the first studies on vitamin $\mathrm{E}$, a reduction in plaque size was reported in $91 \%$ of patients and decreased curvature in $78 \%$. In the literature published between 1952-1982, there are $0-70 \%$ response rates when $200-800 \mathrm{mg}$ of vitamin $\mathrm{E}$ is used daily. At the NIH Conference on Peyronie's disease in 1993, Devine and Snow presented a study in which 105 patients taking oral vitamin $\mathrm{E}$ reported a $99 \%$ reduction in pain and a $13 \%$ reduction in penile curvature. No objective change was observed in $70 \%$ of the patients. Studies have shown that vitamin $\mathrm{E}$ affects reducing penile pain, and it affects penile curvature and plaque size relatively less (6, 7).

\section{Colchicine}

\section{Mechanism}

Colchicine is an alkaloid obtained from colchicum autumnale. It is an anti-inflammatory agent that inhibits collagen synthesis and stimulates collagenase activity. It has important effects in both the inflammatory and fibrotic stages of the disease.

\section{Evidence}

An uncontrolled study reported a slight reduction in curvature in $11 \%$, a significant reduction in curvature in $26 \%$, and a reduction in plaque size in $50 \%$. However, there was no improvement in hourglass deformity and hardening. Levine reported that more than half of the more than 30 patients treated with colchicine had gastrointestinal disturbances $(7,8)$. Colchicine is used $2 \mathrm{mg} /$ day for 3-6 months in the treatment of Peyronie's disease. Studies have shown significant improvements in penile pain and curvature, with reduction or disappearance of penile plaques. Apart from gastrointestinal side effects, side effects such as fever, skin rashes, agranulocytosis, aplastic anemia, myopathy, and angioneurotic edema have also been observed (9).

Better results can be obtained when colchicine and vitamin $\mathrm{E}$ are used together. It has been reported to show significant improvement in plaque size and curvature, especially in early-stage disease $(6,10)$.

\section{Phosphodiesterase Type 5 Inhibitors (PDE-5I)}

\section{Mechanism}

Activation of the nitric oxide pathway by phosphodiesterase type 5 inhibitors (PDE5is) plays a role in improving erectile function, suppressing collagen synthesis, and initiating apoptosis of myofibroblasts (11).

\section{Evidence}

Long-term administration of PDE5i in animal experiments showed increased collagen and a decrease in fibroblasts 
in tunica albuginea cells $(12,13)$. PDE5i was therefore investigated for its effects on plaque formation and remodeling in Peyronie's disease. In one study, 39 Peyronie's patients were administered daily sildenafil or vitamin $\mathrm{E}$ for three months. A similar reduction in plaque size was seen, but a statistically more significant improvement in pain reduction scores and erectile function was documented in the Sildenafil group compared to the vitamin E group (14). In another retrospective controlled study, 65 patients with isolated septal scars (ISS) without evidence of penile deformity were treated for six months without treatment. Follow-up and daily use of $2.5 \mathrm{mg}$ tadalafil were compared. The resolution of septal scars was $10 \%$ and $69 \%$, respectively, in the untreated and tadalafiltreated groups (15). Finally, a newer RCT, extracorporeal shock wave therapy, and a combination of tadalafil 5 $\mathrm{mg}$ once daily improved the erectile function score but significantly reduced penile curvature and plaque size. It was documented that it did not change significantly.

\section{Carnitine}

\section{Mechanism}

Acetyl-L-carnitine and propionyl-L-carnitine, a derivative of carnitine, are inhibitors of acetyl coenzyme-A that help repair damaged DNA and prevent free radical formation during cell stress $(16,17)$.

\section{Evidence}

It has been shown that propionyl-L-carnitine (PLC) regulates the amount of intracellular calcium and reduces penile fibrosis by controlling collagen production and fibroblast proliferation in endothelial cells $(8,18)$. In a study conducted by Cavallini and Biagiotti in 2001 involving 48 Peyronie's patients, patients were treated with $20 \mathrm{mg}$ of tamoxifen and were given twice a day for three months. Acetyl-L-carnitine was found to be more effective than tamoxifen in reducing curvature and pain and preventing disease progression. Both drugs were found to be equally effective in reducing the amount of penile plaque size (19). In a study conducted by the same group in 2002, the combination of intralesional Verapamil (10mg per week for ten months) and PLC ( $2 \mathrm{~g} /$ day for three months) was combined with tamoxifen reported to give better results compared.

\section{Q-10}

\section{Mechanism}

Q10; It is a lipophilic, organic, vitamin-like, and potent antioxidant found in the body $(1,20,21)$. It has a role in protecting cells against ischemia, oxidative stress, and oxidative damage by polyunsaturated fatty acids. People with Peyronie's disease have inflammation and overexpression of the TGF pathway in their fibroblasts. Q10 activates Nrf2, which increases antioxidant proteins that protect against oxidative damage activated by inflammation. Nrf2 suppresses the expression of TGF-21. In addition, the increase in oxidative stress damages the tissue, and it has been said that Nrf2 can indirectly initiate cell division for this injury (21).

\section{Evidence}

Overexpression of Nrf2 in experiments with Q10, mouse liver, and embryonic fibroblast cells; Expressions of alpha-smooth muscle actin and TGF-21 were suppressed (21). In a prospective, double-blind, placebo-controlled randomized study, an improvement in curvature was observed in $54.3 \%$ of patients and a $40 \%$ reduction in plaque size; these rates were lower in the placebo group. The increase in curvature was $14.8 \%$ in Q10 and $69.5 \%$ in placebo. In erectile function, it was $51.9 \%$ versus $8.6 \%$ in placebo.2 As a result, in studies conducted; Since there is a decrease in penile curvature and plaque size and improvement in erectile function, it can be said that Q10 has a protective effect on the course of the disease (22).

\section{Potassium Para-amino Benzoate (POTABA)}

\section{Mechanism}

POTABA, first used for Peyronie's disease in 1959, is an anti-inflammatory and antifibrotic drug that inhibits abnormal fibroblast growth and secretion of extracellular fluid components $(1,5,23)$. POTABA; It reduces fibrogenesis by increasing the oxygen uptake of the tissue and supporting the activity of monoamine oxidase, which enables the breakdown of serotonin (24).

\section{Evidence}

In a double-blind, placebo-controlled study, POTABA showed a $74.3 \%$ reduction in plaque size compared to placebo, but no difference was found in curvature and pain $(22,24)$. Researchers said that POTABA prevented and stabilized the degree of curvature $(22,25)$. It is not commonly used because it has itching, anxiety, chills, cold sweats, confusion, difficulty in concentration, and severe gastrointestinal side effects and is expensive $(24,26)$. It has also been reported in a study that it may cause hepatitis (27). It is taken in 4 doses of 3 grams per day, and Its use is also limited due to the high daily dose (22). For these reasons, data on the efficacy of POTABA are scarce (28). 


\section{Oral Treatment Methods Summary}

Studies have shown that colchicine and POTABA have some severe side effects. Evidence on the effectiveness of oral treatments is insufficient, and there are few RCT studies $(23,29)$. In the guideline published by the EAU in 2019, it is recommended that vitamin E should not be used in patients who want to significantly reduce the curvature. According to the International Consultation on Sexual Medicine 2016 guideline (ICSM), oral treatments have been reported to be minimally beneficial or not beneficial in reducing the clinical features of Peyronie's disease; therefore, their use is not recommended $(30,31)$.

\section{TOPICAL THERAPY METHODS}

\section{Verapamil}

\section{Mechanism}

Verapamil is used as a calcium channel blocker in the treatment of Peyronie's disease. In this way, it is aimed to increase collagenase activity and to prevent the secretion of extracellular fluid proteins (32).

\section{Evidence}

Studies are continuing on the use of Verapamil, which is also used intralesional, as a topical treatment method. There are data in some studies that Verapamil does not reach the tunica albuginea (33), but dexamethasone and Verapamil applied by ionotophoresis have been shown to reduce the curvature, especially in patients with a curvature degree of less than $(30,34)$.

At the same time, a guideline published by the EAU in 2019 stated that topical Verapamil reduces penile curvature and plaque size (35).

\section{H-100 Gel}

\section{Mechanism}

H-100, topically applied for the non-surgical treatment of Peyronie's disease, it is a gel with the chemical content of Nicardipine, superoxide dismutase, and emu oil. Emu oil, rich in fatty acids, has been used as a transdermal carrier agent (36). Superoxide dismutase provides clearance of free oxygen radicals that play a role in inflammation (37). Nicardipine is a calcium channel blocker. It may also be effective in reducing glycosaminoglycan synthesis and blocking collagen production (38).

\section{Evidence}

In a randomized, double-blind, placebo-controlled study to evaluate the efficacy and safety of $\mathrm{H}-100,22$ patients with acute-phase Peyronie's disease were examined. During the first three months, half of the patients received $\mathrm{H}-100$, and the other half received a placebo. For the next three months, all patients received H-100. An increase in penile length $(22.6 \%)$, a decrease in curvature $(40.8 \%)$, and a decrease in pain level (85.7\%) were observed in patients who received $\mathrm{H}-100$ for six months. An increase in penile length (6.8\%) was observed in patients who received a placebo for the first three months, but no improvement was observed in other parameters. Patients who started taking H-100 after taking a placebo had an increase in penile length $(17.5 \%)$, a decrease in curvature (37.1\%), and a decrease in pain level $(40 \%)$. The treatment had side effects in only three patients, which was self-limiting skin rash. Although this study yielded positive results, due to the small size of the study, more data on $\mathrm{H}-100$ are needed before routine use (39).

\section{Liposomal Recombinant Human Superoxide Dismutase (Liposomal RHSD)}

\section{Mechanism}

In the treatment of liposomal RHSD, a topical gel containing superoxide dismutase is applied to the patient. Theoretically, the aim is to stop the inflammatory steps as a result of superoxide dismutase breaking down free oxygen radicals and throwing them out of the body, and thus slowing down and limiting the progression of the disease.

\section{Evidence}

In placebo, controlled randomized clinical trials, 39 patients suffering from bothersome pain from Peyronie's disease were treated with liposomal RHSD and placebo, and when observed for 4-week periods, significant pain reduction was observed after 28 days compared to placebo. At the end of 56 days, $89 \%$ of the patients who were treated with liposomal RHSD had a significant reduction in their pain. Recovery in other symptoms of the disease occurred on the 84th day. Plaque consistency decreased in $38 \%$ of patients, plaque size decreased by $47 \%$, and improved penile curvature by 5-30 degrees in $23 \%$ of patients. Liposomal RHSD treatment also reduced the rate of disease progression, which rose to $40 \%$, to less than $10 \%$. In conclusion, while liposomal RHSD treatment in Peyronie's disease reduced pain, it also showed improvements in other symptoms (40). 


\section{Transdermal Electromotive Drug Administration (EMDA)}

In this method, also known as iontophoresis, the aim is to deliver the drug to be applied to the tunica albuginea tissue in the targeted area. Transdermal transfer of the therapeutic agent is achieved by electrokinetic transport of charged molecules (41). There are also studies indicating that this method is more effective in reducing erectile pain than intralesional applied dexamethasone and Verapamil (42).

\section{Topical Treatment Methods Summary}

Research continues on the adequacy of topical treatment methods. Although there are studies showing that it can be effective in reducing curvature and pain, there is no topical treatment method approved by the FDA yet. Although there are studies showing that topical Verapamil and EMDA may work, as stated in the EAU guidelines, there is no data to provide a definitive solution.

\section{TRACTION AND VACUUM TREATMENTS}

\section{Penile Traction Therapy}

\section{Mechanism}

This treatment is performed using the penile traction device (PTD). The PTT works by holding the penis in the cradle and subjecting it to gentle and gradual traction forces that can be achieved by adding dynamic rods and small metal extensions to the cradle frame every few weeks (43).

\section{Evidence}

In in vitro studies, it has been determined that the secretion of matrix metalloproteinase-8 (MMP-8), which has an effect on collagen degradation, increases significantly while it is under the effect of traction in penile plaque tunica albuginea cells. PTT plays a role in the rearrangement of these collagen fibrils and in reducing the activity of myofibroblast cells.

In men with early-stage Peyronie's disease, when the traction device was used for at least 4 hours a day for a total of 3-6 months, an increase in mean penile length and a $14^{\circ}$ decrease in mean erect penile curvature were observed (44). When PTT was applied to Peyronie's patients in a stable period for an average of five hours per day for six months, approximately 17 degrees (33\%) improvement in penile curvature was observed. An increase in erect penis circumference and flaccid penile length has been observed (45). In men with at least 12 months of Peyronie's disease and pre-existing curvature below $50^{\circ}$, penile curvature decreased from $31^{\circ}$ to $27^{\circ}$ on average as a result of using the traction device for 5-9 hours a day has fallen. As a result, no significant improvement in penile curvature was observed (46). In acute phase Peyronie's patients, a decrease of approximately 20 degrees in penile curvature, a significant increase in erectile function, and a significant improvement in penile pain were observed when PTT was applied between 6-9 hours daily for a minimum of 6 months. In $40 \%$ of the patients, the need for surgery disappeared (47).

In a randomized controlled study using a new device called "Penimaster PRO" in men with stable Peyronie's disease and a minimum of 45 degrees penile curvature, after 3-8 hours of PTT per day for 12 weeks, an improvement of approximately 31 degrees was observed in penile curvature and the daily application time was increased (48).

In men with stable Peyronie's disease and a minimum of 30 degrees penile curvature, "RestoreX" a new traction device, was applied daily for 30-90 minutes for three months, and a decrease of approximately 12 degrees in penile curvature and an average increase of $1.5 \mathrm{~cm}$ in penile length were observed (49).

\section{Vacuum Erection Device (VED)}

\section{Mechanism}

VED treatment is performed with devices that create negative pressure to induce events such as retrograde venous blood flow, enlargement of the cavernous sinuses, and increased arterial blood flow.

\section{Evidence}

As a result of the use of VED 2 times a day (10 minutes), reduction in penile pain, approximately 0.5 $\mathrm{cm}$ elongation in erect penis length, and 5-25 degree decrease in curvature were observed (50).

An average of 16 degrees improvement in penile curvature was seen in men who used VEDs for 10-minute periods twice a day for 11 months. In addition, it was understood that the improvement was not related to the patient's age and that the treatment gave better results in patients with a high degree of curvature (51). 


\section{Traction and Vacuum Therapies Summary:}

In recent years, VED and PTT have received great attention as a new non-surgical treatment option for Peyronie's disease. These seemingly safe and well-tolerated nonsurgical treatments require a great deal of patient compliance and commitment. Current literature suggests that selected cases may benefit from a conservative approach with PTT and VED, resulting in a reduction in penile deformity.

Evidence for PTT is limited. However, while some studies did not show significant improvement, several studies have shown a potential benefit of PTT when used as monotherapy or in combination with oral medications, intralesional injections, or surgery, with significant improvement in curvature reduction, erectile function, and penile pain. In addition, PTT was found to be more effective in acute phase Peyronie's patients, and some patients did not require surgery. Future studies will identify key points, including issues of patient compliance and duration of use. Although there are not many studies on VED treatment, a significant improvement was observed in Peyronie's patients, and some patients did not require surgical intervention. More studies on this treatment are needed.

\section{SHOCK WAVE THERAPY}

\section{Extracorporeal Shock Therapy (ESWT)}

\section{Mechanism}

Although the mechanism of action of ESWT has not yet been clearly revealed, it is a form of treatment that aims at the effect of acoustic pressure waves sent from the outside to the body, defines the energy size per $\mathrm{mm}^{2}$, and its density is measured in $\mathrm{mJ} / \mathrm{mm}^{2}$.

\section{Evidence}

ESWT was first described in 1989 by Bellorofonte C et al. Although it was applied to patients with cavernous fibrosis due to Peyronie's disease, it was applied by Butz and Teichert in 1996 considering that it would be a welltolerated method. In the study, 52 patients were used and followed up for nine months. $83 \%$ reduction in pain, $40 \%$ improvement in curvatures, and 48\% improvement in sexual functions were observed. If we look at the recent studies that measured the effectiveness of ESWT in Peyronie's disease; We consider one as randomized without placebo/sham group, three as RCT, and the rest as observational studies. In the studies, treatment methods were applied once a week for 4-6 weeks with an energy density of $0.25-0.29 \mathrm{~mJ} / \mathrm{mm}^{2}$ and the number of pulses varying between 2000-3000. Attention was paid to the fact that the patients included in the study were stable for more than six months without any previous treatment, and at least three months old who received oral treatment before and failed. Hatzichristodoulou et al. (52), while statistically similar percentages were found between the change of curvature and plaque size in the active treatment group and the sham group in the RCT, it was observed that the ESWT treatment group showed greater improvement in the mean pain over VAS than the placebo/sham group. In addition, in this study, $85 \%$ reduction in pain was observed in the ESWT group, while the pain reduction was $48 \%$ in the placebo/sham group. In 2009 Palmieri et al. (53) study, 100 patients with Peyronie's disease under 12 months were divided into control group and ESWT. The age range was 18-75 years, and the patients were followed for 1224 weeks in terms of painful erection, plaque size, erectile function, penile curvature, and quality of life. There was an insignificant reduction in curvature and plaque size in the ESWT group, while a small increase was found in the placebo/sham group. In this study, the mean pain over VAS was also looked at, and it was observed that ESWT from the two groups provided more improvement than the placebo / sham group. In 2004, Hauck et al. in the metaanalysis of; It has been stated that the success in ESWT is in very wide ranges such as $0-74 \%$ for penile curvature, $0-58 \%$ for plaque size, $12-75 \%$ for sexual function and $56-$ $100 \%$ for penile pain. In the meta-analysis; It was stated that ESWT treatment did not statistically change the degree of curvature, plaque size, and erection score; only after treatment it reduced pain from $37 \%$ to $9 \%$, and ESWT application statistically reduced penile pain (54).

\section{Shock Wave Therapy Summary}

ESWT is a treatment based on sending shock waves from outside to the body. ESWT experiments showed that the degree of curvature, plaque size, and pain decreased, while the erection score increased when first performed. However, in the experiments conducted in the following years, the degree of curvature does not significantly change plaque size, erection score but significantly reduces pain.

\section{PLAQUE INJECTION TREATMENTS}

\section{Interferon-Alfa-2B}

\section{Mechanism}

Interferons are low molecular weight proteins and glycoproteins responsible for immunoregulation that can 
be synthesized endogenously in the human body. In vitro studies have shown that interferon-alpha $2 b$ (INF- $\alpha-2 b$ ) suppresses fibroblast proliferation with its antifibrotic effect, decreases collagen and extracellular matrix production in fibroblast cells, and increases collagenase production (51)

\section{Evidence}

In the first study, plaque softening, 50\% reduction in curvature, and total pain relief were reported. A 1x10unit dose of INF- $\alpha-2 b$ was injected subcutaneously into the plates in a later study. Post-injection pain relief has been reported, with a reduction in $28 \%$ of non-calcified or minimally calcified plaques size. Following this treatment, the amount of the drug was increased $\left(3 \times 10^{6}\right.$ unit dose IFN- $\alpha-2 b$ ), and the same treatment was applied, resulting in no reduction in plaque and $82 \%$ of side effects were observed. In another study, pain relief, reduction in penile curvature, plaque softening, and reduction in plaque size were reported in patients who received intralesional saline as control and $1.5 \times 10^{6}$ units of IFN- $\alpha-2 b$ injection as a treatment (55).

In the most scientifically finalized study of the efficacy of intralesional INF- $\alpha-2 b$ in Peyronie's disease, $5 \times 10^{6}$ INF- $\alpha$ $2 \mathrm{~b}$ was administered to patients. Penile curvature, plaque characteristics (size, density), penile pain, erectile function, and penile hemodynamic parameters were evaluated in the study. At the end of this study, mean penile curvature decreased from 49.9 degrees to 36.4 degrees, mean plaque size reduced by $4.8 \mathrm{~cm}$ to 2.2 , mean plaque density decreased from 2.07 to 1.84 , pain resolution was $67.7 \%$ of patients a decrease in of them, and an increase in penile blood flow was observed. However, no difference in mean erectile function was observed. These results provide the best evidence of efficacy to support the use of intralesional interferon in patients.

Taking an overdose of IFN- $\alpha-2 b$ has side effects such as flu-like syndrome, anorexia, rashes, hypotension, and cardiac arrhythmia. The use of analgesic drugs before intralesional injection of INF- $\alpha-2 b$ reduces these side effects (9).

\section{Clostridium Collagenase Histolicum (CCh)}

\section{Mechanism}

CCh, which is a mixture of AUX-I and AUX-II enzymes produced by Clostridium histolyticum bacteria, both reduces the abnormal expression of type 1 and 3 collagens by enzymatically disrupting the triple helix structure in pathological collagen plaques in Peyronie's disease and destroys these plaques that cause PD curvature.

This enzyme does not act on arteries, nerves, and surrounding connective tissues containing collagen type 4. 54 The efficacy of collagenase treatment on plaque tissue was discovered in 2013 with the phase 3 IMPRESS trial and in vitro studies (56). As a result, $\mathrm{CCh}$, which has demonstrated efficacy and safety in clinical trials for the conservative treatment of Peyronie's disease, has become the only FDA-approved treatment (57).

\section{Evidence}

A double-blind, randomized, placebo-controlled study involving 418 patients was completed in 4 treatment cycles of 2 injections 24-72 hours apart. Curvature, erectile function improved, pain, and plaque size decreased (58). In a retrospective cohort study of 918 patients treated between April 2014 and March 2018 and collected from 5 different institutions, penile curvature decreased from an average of 48.2 degrees before treatment to 32.9 degrees after treatment, and it was determined that there was an improvement of $30.1 \%$ compared to the baseline. $68.7 \%$ of patients had $20 \%$ or more improvement in penile curvature. In 502 patients who completed four or more cycles of treatment, penile curvature decreased from an average of 49.7 degrees to 32.7 degrees and showed a $33 \%$ improvement from baseline. Of these patients, $74.4 \%$ experienced $20 \%$ or greater improvement in curvature. Treatment complications developed in $9 \%$ of the patients. The number of CCh cycles received was a predictor of curvature improvement. This multi-institutional metaanalysis confirms the safety and efficacy of CCh therapy in men with Peyronie's disease (59). Improvements in penile curvature and Peyronie's Disease Questionnaire score continued without additional CCh therapy up to 5 years after intralesional CCh therapy, and no problems were identified (60)

Most adverse events associated with intralesional CCh therapy (hematoma, bruising, pain, and swelling in the penis) were mild or moderate and resolved without intervention. In addition, the use of $\mathrm{CCH}$ was not associated with penile shortening (61). In the sexual function questionnaire, in which a total of 24 couples participated, the satisfaction of the patient and the female sexual partner with the treatment was $67 \%$ and $71 \%$, respectively. As a result, $\mathrm{CCH}$ treatment provides a significant benefit to a couple's sexual health. Treatment is associated with increased partner satisfaction and increased ability to have sexual intercourse $(62,63)$. 


\section{Verapamil}

\section{Mechanism}

Verapamil, a calcium channel blocker, was first described in 1994 by Levine et al. it has been shown that it can be used in Peyronie's treatment because it changes the metabolism of fibroblasts, inhibits calcium-dependent extracellular collagen transport, and increases collagenase activity (64).

\section{Evidence}

In a meta-analysis of seven different studies, intralesional injection of Verapamil significantly improved sexual function $(\mathrm{p}<0.0005)$ and penile curvature $(\mathrm{p}<0.005)$ in patients. There is an imprecise but significant reduction in pain after the treatment, but less effect on plaque size ( $p>$.05) (65). In a prospective, single-blind, randomized study, the use of Verapamil in Peyronie's disease showed improvement in penile curvature and reduction in plaque size (66).

Verapamil injection is clinically safe for patients with Peyronie's disease and appears to cause a rapid and beneficial effect in patients for reducing plaque size. Intralesional injection of Verapamil for Peyronie's disease can reduce pain, reduce penile curvature, and improve sexual function (32).

\section{Nicardipine}

\section{Mechanism}

Following the success of Verapamil used in the treatment of Peyronie's disease, universities began to conduct randomized placebo-controlled studies on the potency of Nicardipin-a dihydropyridine based on this treatment (calcium channel blocker). Compared with Verapamil, the possibility of its high efficacy in reducing extracellular substance synthesis between the acute and chronic phases of Peyronie's disease was considered.

\section{Evidence}

The study included 74 randomly selected men. Patients are given Nicardipine (10 $\mathrm{mg}$ in $10 \mathrm{ml}$ of distilled water) or $10 \mathrm{ml}$ of normal saline every two weeks for ten weeks (6 doses in total). The clinical outcomes evaluated were pain during erection, plaque size, erectile function (according to the international index of erectile function 5 [IIEF-5]), and penile curvature.

While the pain was more pronounced in the nicardipine group, it decreased in both groups (p: 0.019). At 48 weeks, significant improvements in mean IIEF-5 score and plaque size were noted in the nicardipine group only $(\mathrm{p}<0.0001$ and p: 0.0004 , respectively). Penile slope improved significantly and to a similar extent in both groups at the end of the study, consistent with previous Verapamil studies $(67,68)$.

\section{Intraplaque Injection Therapy Summary}

As a result of studies with intralesional IFN- $\alpha-2 b$, it is suitable for use in treatment, as the use of the right amount shows a significant improvement in patients. Intralesional $\mathrm{CCh}$ and intralesional verapamil treatment can be used clinically in Peyronie's disease as it improves curvature, erectile function and reduces pain and plaque size. As a result of the study, the authors concluded that Nicardipine is an alternative and effective option for patients with transitional phase Peyronie's disease. Nevertheless, it is thought that the search for a non-surgical treatment for Peyronie's disease should continue.

\section{EXPERIMENTAL TREATMENTS}

\section{Stem Cell Therapy}

\section{Mechanism}

Adipose tissue-derived regenerative cell (ADSC or SVF) treatment is based on enzymatic reactions of approximately $50 \mathrm{cc}$ of fat taken from the sides of the penis. This fluid, which decreases as a result of enzymatic reactions, is injected into the body from the right and left sides of the penis. In Peyronie's disease, we inject it into the plaque in the penis. However, injecting this liquid alone is not enough. At least six sessions of shock wave therapy should also follow this process because shock wave therapy stimulates stem cells and activates them.

Of course, this treatment is not only used in Peyronie's patients. It is also generally used in patients with erectile dysfunction.

\section{Evidence}

In animal experiments, TGF- 11 was given to rats treated with ADSC. After this situation, it was noticed that the development of Peyronie's disease was prevented. In addition, it was determined that elastic tissue and type 3 collagen tissue decreased.68 In an article published in 2016, a table was given as a result of the application of ADSC and shock wave together. According to this table, the penile hardness of 7 of 11 participants increased. One of the remaining four people already had a normal erection. 
The other 3 had an erection that would allow them to have sexual intercourse, although it was not normal. In total, the degree of hardening score increased from 2.7 to 3.5 on average (69).

\section{Experimental Treatments Summary}

Stem cell therapy is known as a complicated and new treatment method that is applied with the support of liquid injection and then shock wave therapy. In experiments, it was noted that it prevented the development of Peyronie's disease and reduced the production of type 3 collagen. It has been found to increase the degree of hardening.

\section{REFERENCES}

1. Ory J, MacDonald L, Langille G. Noninvasive Treatment Options for Peyronie's Disease. Sex Med Rev. 2020;8(4):603-614.

2. Paulis G, Romano G, Paulis A. Prevalence, psychological impact, and risk factors of erectile dysfunction in patients with Peyronie's disease: a retrospective analysis of 309 cases. Res Rep Urol. 2016;8:95-103.

3. Sasso F, Gulino G, Falabella R, D'Addessi A, Sacco E, D'Onofrio A et al. Peyronie's disease: lights and shadows. Urol Int. 2007;78(1):1-9.

4. Patel DP, Christensen MB, Hotaling JM, Pastuszak AW. A review of inflammation and fibrosis: implications for the pathogenesis of Peyronie's disease. World J Urol. 2020;38(2):253-261.

5. Armağan A, Soyupek S, Hoşcan B. Peyronie hastalığının medikal tedavisindeki yenilikler. Androloji Bülteni. 2004;6(17):93-98

6. Hussein AA, Alwaal A, Lue TF. All about Peyronie's disease. Asian J Urol. 2015;2(2):70-78.

7. Hellstrom WJ, Bivalacqua TJ. Peyronie's disease: etiology, medical, and surgical therapy. J Androl. 2000;21(3):347-54.

8. Mynderse LA, Monga M. Oral therapy for Peyronie's disease. Int J Impot Res. 2002;14(5):340-4.

9. Akkus E, Yıldırım Ö. Peyronie hastalığı. In: Doğan HS, editor. Ürolojik Cerrahi Kitabı. İstanbul:Galenos; 2020. p. 289-319

10. Prieto Castro RM, Leva Vallejo ME, Regueiro Lopez JC, Anglada Curado FJ, Alvarez Kindelan J, Requena Tapia MJ. Combined treatment with vitamin $\mathrm{E}$ and colchicine in the early stages of Peyronie's disease. BJU Int. 2003;91(6):522-4.

11. Vernet D, Ferrini MG, Valente EG, Magee TR, Bou-Gharios G, Rajfer $\mathrm{J}$ et al. Effect of nitric oxide on the differentiation of fibroblasts into myofibroblasts in the Peyronie's fibrotic plaque and in its rat model. Nitric Oxide. 2002;7(4):262-76

12. Valente EG, Vernet D, Ferrini MG, Qian A, Rajfer J, Gonzalez-Cadavid NF. L-arginine and phosphodiesterase (PDE) inhibitors counteract fibrosis in the Peyronie's fibrotic plaque and related fibroblast cultures. Nitric Oxide. 2003;9(4):229-44

13. Ferrini MG, Kovanecz I, Nolazco G, Rajfer J, Gonzalez-Cadavid NF. Effects of long-term vardenafil treatment on the development of fibrotic plaques in a rat model of Peyronie's disease. BJU Int. 2006;97(3):625-33.

14. Ozturk U, Yesil S, Goktug HN, Gucuk A, Tuygun C, Sener NC et al. Effects of sildenafil treatment on patients with Peyronie's disease and erectile dysfunction. Ir J Med Sci. 2014;183(3):449-53.

15. Chung E, Deyoung L, Brock GB. The role of PDE5 inhibitors in penile septal scar remodeling: assessment of clinical and radiological outcomes. J Sex Med. 2011;8(5):1472-7.
16. Palmieri A, Imbimbo C, Creta M, Verze P, Fusco F, Mirone V. Tadalafil once daily and extracorporeal shock wave therapy in the management of patients with Peyronie's disease and erectile dysfunction: results from a prospective randomized trial. Int J Androl. 2012;35(2):190-5.

17. Bremer J. Carnitine--metabolism and functions. Physiol Rev. 1983;63(4):1420-80.

18. Yafi FA, Pinsky MR, Sangkum P, Hellstrom WJ. Therapeutic advances in the treatment of Peyronie's disease. Andrology. 2015;3(4):650-60.

19. Biagiotti G, Cavallini G. Acetyl-L-carnitine vs tamoxifen in the oral therapy of Peyronie's disease: a preliminary report. BJU Int. 2001;88(1):63-7.

20. Cavallini G, Biagiotti G, Koverech A, Vitali G. Oral propionyl-1carnitine and intraplaque Verapamil in the therapy of advanced and resistant Peyronie's disease. BJU Int. 2002;89(9):895-900.

21. Safarinejad MR. Safety and efficacy of coenzyme Q10 supplementation in early chronic Peyronie's disease: a double-blind, placebo-controlled randomized study. Int J Impot Res. 2010;22(5):298-309

22. Amasyalı AS. Peyronie hastalığının medikal tedavisinde neler değişti: 2015 güncelleme. Androloji bülteni.2015;17(62): 169-173169-173.

23. Russo GI, Cacciamani G, Cocci A, Kessler TM, Morgia G, Serefoglu EC, et al. Comparative Effectiveness of Intralesional Therapy for Peyronie's Disease in Controlled Clinical Studies: A Systematic Review and Network Meta-Analysis. J Sex Med. 2019 Feb;16(2):289-299.

24. Levine LA. Peyronie's disease: A contemporary review of non-surgical treatment. Arab J Urol. 2013;11(3):278-83.

25. Weidner W, Hauck EW, Schnitker J; Peyronie's Disease Study Group of Andrological Group of German Urologists. Potassium paraaminobenzoate (POTABA) in the treatment of Peyronie's disease: a prospective, placebo-controlled, randomized study. Eur Urol. 2005;47(4):530-5; discussion 535-6

26. Hellstrom WJ. Medical management of Peyronie's disease. J Androl. 2009 Jul-Aug;30(4):397-405.

27. Roy J, Carrier S. Acute hepatitis associated with treatment of Peyronie's disease with potassium para-aminobenzoate (Potaba). J Sex Med. 2008;5(12):2967-9

28. Shaw EJ, Mitchell GC, Tan RB, Sangkum P, Hellstrom WJ. The nonsurgical treatment of peyronie disease: 2013 update. World J Mens Health. 2013;31(3):183-92.

29. Chung E, Ralph D, Kagioglu A, Garaffa G, Shamsodini A, Bivalacqua T, Glina S, Hakim L, Sadeghi-Nejad H, Broderick G. EvidenceBased Management Guidelines on Peyronie's Disease. J Sex Med. 2016;13(6):905-23

30. El-Sakka AI, Salabas E, Dinçer M, Kadioglu A. The pathophysiology of Peyronie's disease. Arab J Urol. 2013;11(3):272-7.

31. Randhawa K, Shukla CJ. Non-invasive treatment in the management of Peyronie's disease. Ther Adv Urol. 2019;11:1756287218823671.

32. Asali M, Asali M. Intralesional injection of the calcium channel blocker Verapamil in Peyronie's disease: A critical review. Arch Ital Urol Androl. 2020;92(3).

33. Martin DJ, Badwan K, Parker M, Mulhall JP. Transdermal application of verapamil gel to the penile shaft fails to infiltrate the tunica albuginea. J Urol. 2002;168(6):2483-5.

34. Kokab A, Wylie K, Allen P, Shetty A, Davies-South D. Structured SelfRated Response to Iontophoresis with Verapamil and Dexamethasone in Peyronie's Disease. Adv Urol. 2014;957013.

35. Hatzimouratidis, K., F. Giuliano, I. Moncada, A. Muneer and A. Salonia. EAU guidelines on erectile dysfunction, premature ejaculation , penile curvature and priapism. 2017. Available at https://uroweb. org/wp-content/uploads / 16-Male-Sexual-Dysfunction_2017_web. pdf. Accessed May 20, 2021 
36. Zemtsov A, Gaddis M, Montalvo-Lugo VM. Moisturizing and cosmetic properties of emu oil: a pilot double blind study. Australas J Dermatol. 1996;37(3):159-61.

37. Kinnula VL, Crapo JD. Superoxide dismutases in the lung and human lung diseases. Am J Respir Crit Care Med. 2003;167(12):1600-19.

38. Kouoh F, Gressier B, Dine T, Luyckx M, Brunet C, Ballester L, Cazin JC. Antioxidant effects and anti-elastase activity of the calcium antagonist nicardipine on activated human and rabbit neutrophils--a potential antiatherosclerotic property of calcium antagonists? Cardiovasc Drugs Ther. 2002;16(6):515-20.

39. Twidwell J, Levine L. Topical treatment for acute phase Peyronie's disease utilizing a new gel, H-100: a randomized, prospective, placebo-controlled pilot study. Int J Impot Res. 2016;28(2):41-5.

40. Riedl CR, Sternig P, Gallé G, Langmann F, Vcelar B, Vorauer K et al. Liposomal recombinant human superoxide dismutase for the treatment of Peyronie's disease: a randomized placebo-controlled double-blind prospective clinical study. Eur Urol. 2005;48(4):656-61.

41. Canadian Agency for Drugs and Technologies in Health Rapid Response Reports. The use of the electromotive drug administration system in patients with overactive bladder: A review of the clinical effectiveness, safety, and cost-effectiveness. Ottawa (ON). 2014. Available at https://www.ncbi.nlm.nih.gov/books/NBK253337/. Accessed May 22, 2021

42. Mehrsai AR, Namdari F, Salavati A, Dehghani S, Allameh F, Pourmand G. Comparison of transdermal electromotive administration of Verapamil and dexamethasone versus intra-lesional injection for Peyronie's disease. Andrology. 2013;1(1):129-32.

43. Valenzuela R, Ziegelmann M, Tokar S, Hillelsohn J. The use of penile traction therapy in the management of Peyronie's disease: current evidence and future prospects. Ther Adv Urol. 2019;11:1756287219838139.

44. Scroppo FI, Mancini M, Maggi M, Colpi GM. Can an external penis stretcher reduce Peyronie's penile curvature? Int J Impot Res. 2001;13(4)

45. Levine LA, Newell M, Taylor FL. Penile traction therapy for treatment of Peyronie's disease: a single-center pilot study. J Sex Med. 2008;5(6):1468-73.

46. Gontero P, Di Marco M, Giubilei G, Bartoletti R, Pappagallo G, Tizzani A et al. Use of penile extender device in the treatment of penile curvature as a result of Peyronie's disease. Results of a phase II prospective study. J Sex Med. 2009;6(2):558-66.

47. Martínez-Salamanca JI, Egui A, Moncada I, Minaya J, Ballesteros CM, Del Portillo L et al. Acute phase Peyronie's disease management with traction device: a nonrandomized prospective controlled trial with ultrasound correlation. J Sex Med. 2014;11(2):506-15.

48. Moncada I, Krishnappa P, Romero J, Torremade J, Fraile A, MartinezSalamanca JI et al. Penile traction therapy with the new device 'Penimaster PRO' is effective and safe in the stable phase of Peyronie's disease: a controlled multicentre study. BJU Int. 2019;123(4):694-702.

49. Ziegelmann M, Savage J, Toussi A, Alom M, Yang D, Kohler T et al. Outcomes of a Novel Penile Traction Device in Men with Peyronie's Disease: A Randomized, Single-Blind, Controlled Trial. J Urol. 2019;202(3):599-610.

50. Raheem AA, Garaffa G, Raheem TA, Dixon M, Kayes A, Christopher $\mathrm{N}$ et al. The role of vacuum pump therapy to mechanically straighten the penis in Peyronie's disease. BJU Int. 2010;106(8):1178-80.

51. MacDonald LP, Armstrong ML, Lehmann KJ, Acker MR, Langille GM. Outcome analysis of patients with Peyronie's disease who elect for vacuum erection device therapy. Can Urol Assoc J. 2020;14(9):E428-E431.

52. Hatzichristodoulou G, Meisner C, Gschwend JE, Stenzl A, Lahme S. Extracorporeal shock wave therapy in Peyronie's disease: results of a placebo-controlled, prospective, randomized, single-blind study. J Sex Med. 2013;10(11):2815-21.
53. Palmieri A, Imbimbo C, Longo N, Fusco F, Verze P, Mangiapia F, Creta M, Mirone V. A first prospective, randomized, double-blind, placebocontrolled clinical trial evaluating extracorporeal shock wave therapy for the treatment of Peyronie's disease. Eur Urol. 2009;56(2):363-9.

54. Özyalvaçlı ME, Metin A. Ekstrakorporeal şok dalga tedavisinin androlojideki yeri. 2016;18(65):74-78.

55. Gokce A, Abd Elmageed ZY, Lasker GF, Bouljihad M, Braun SE, Kim $\mathrm{H}$ et al. Intratunical Injection of Genetically Modified Adipose TissueDerived Stem Cells with Human Interferon $\alpha-2 b$ for Treatment of Erectile Dysfunction in a Rat Model of Tunica Albugineal Fibrosis. J Sex Med. 2015;12(7):1533-44.

56. Peak TC, Mitchell GC, Yafi FA, Hellstrom WJ. Role of collagenase clostridium histolyticum in Peyronie's disease. Biologics. 2015;9:10716.

57. Mills SA, Gelbard MK. Sixty years in the making: collagenase Clostridium histolyticum, from benchtop to FDA approval and beyond. World J Urol. 2020;38(2):269-277.

58. Yousif A, Natale C, Hellstrom WJG. Conservative Therapy for Peyronie's Disease: a Contemporary Review of the Literature. Curr Urol Rep. 2021;22(2):6.

59. Seftel AD. Re: Self-Report and Clinical Response to Peyronie's Disease Treatment: Peyronie's Disease Questionnaire Results from 2 Large Double-Blind, Randomized, Placebo-Controlled Phase 3 Studies. J Urol. 2016;195(4 Pt 1):1075.

60. Hellstrom WJG, Tue Nguyen HM, Alzweri L, Chung A, Virasoro R, Tapscott A et al. Intralesional Collagenase Clostridium histolyticum Causes Meaningful Improvement in Men with Peyronie's Disease: Results of a Multi-Institutional Analysis. J Urol. 2019;201(4):777-782.

61. Goldstein I, Lipshultz LI, McLane M, Hu Y, Xiang Q, Liu G et al. LongTerm Safety and Curvature Deformity Characterization in Patients Previously Treated with Collagenase clostridium Histolyticum for Peyronie's Disease. J Urol. 2020;203(6):1191-1197.

62. Hoy SM. Collagenase Clostridium Histolyticum: A Review in Peyronie's Disease. Clin Drug Investig. 2020;40(1):83-92.

63. Anaissie J, Yafi FA, Traore EJ, Sikka SC, Hellstrom WJ. Survey of patient and partner satisfaction following collagenase Clostridium histolyticum treatment for Peyronie's disease. Andrology. 2017;5(2):274-277.

64. Levine LA, Merrick PF, Lee RC. Intralesional verapamil injection for the treatment of Peyronie's disease. J Urol. 1994;151(6):1522-4.

65. Sadagopan A. A snapshot of intralesional verapamil injection in the treatment of Peyronie's disease today. Andrologia. 2019 Nov;51(10):e13388.

66. Toscano L Jr, Rezende MV, Mello LF, Paulillo D, Glina S. A prospective randomized, single - blind study comparing intraplaque injection of thiocolchicine and Verapamil in Peyronie's Disease: a pilot study. Int Braz J Urol. 2016;42(5):1005-1009.

67. Soh J, Kawauchi A, Kanemitsu N, Naya Y, Ochiai A, Naitoh Y et al. Nicardipine vs. saline injection as treatment for Peyronie's disease: a prospective, randomized, single-blind trial. J Sex Med. 2010;7(11):37439

68. Warde N. Therapy: Intralesional Nicardipine: another calcium channel blocker shown to be effective in patients with Peyronie's disease. Nat Rev Urol. 2010;7(11):596.

69. Castiglione F, Hedlund P. Intratunical injection of human adipose tisse-derived stem cells prevents fibrosis and is associated with improved erectile function in a rat model of Peyronie's disease. Eur Urol. 2013;63:551-60 